\title{
Exploring the relationship among psychological safety, knowledge sharing, and innovation
}

\author{
Pari Irai ${ }^{1 *}$, Allan Cheng Chieh $\mathrm{Lu}^{2}$ \\ ${ }^{1,2}$ Institute of International Human Resource Development, National Taiwan Normal University, Taipei, Taiwan
}

\author{
Keywords \\ Psychological safety \\ Knowledge sharing \\ Organizational innovation \\ Social capital
}

Received: 3 April 2018

Accepted: 8 May 2018

Published: 6 June 2018

\begin{abstract}
With the rapid changes in technology and extreme global competition, organizations today have been forced to explore avenues to survive this extreme competition and maintain their competitive edges. Innovation has made it possible for organizations to provide strategic advantages for costs reduction, new product and service disparity, and improved quality. This study explores and explains the connection among employees' perceived psychological safety in the workplace, knowledge sharing, and organizational innovation performance in the context of public sector in Papua New Guinea. This study is a quantitative research using a self-administered questionnaire as the major research instrument to collect the data. The sample of this study were 160 employees of government agencies in Papua New Guinea who have been working in the agency for more than 2 years. The findings show that psychological safety directly affects organizational innovation and an indirect effect on organizational innovation through knowledge sharing. The analytical results provide important practical implications for public sector managers in Papua New Guinea regarding how to encourage employees' knowledge sharing behavior and facilitate organizational innovation performance.
\end{abstract}

(C) 2018 The Author(s). Published by TAF Publishing.

\section{INTRODUCTION}

In the present world of constant changes and aggregate competition, organizations seek new ways to improve their performance in order to remain competitive. Innovation performance is considered crucial for an organization to gain a competitive edge. Extreme global competition, everrapid change of technology, and greater consumers' demands have pressured organizations to identify ways for competitive advantage in order to survive (Black \& Synan, 1997). Likewise, according to Salaman and Storey (2002), nowadays in the global competitive world, Organizational Innovation (OI) is regarded as a critical mechanism for the organization to be more competitive and to survive. Because innovation is regarded as critical for the organizations, it has become imperative to clearly identify the underlying factors that enable innovation competencies and innovation performance. Knowledge Sharing (KS) is at the center of this argument and is explored in this study to investigate its role in innovation competence and innova- tion performance. Barquin (2001) noted that any attempt to improve organizational performance needs to include knowledge sharing initiatives. Knowledge sharing within the organization remains a vital tool that must be embodied within the organization.

Similarly, improving the organization's performance requires multiple characteristics to be embedded in the organization, and Psychological Safety (PS) is another crucial characteristic. Kahn (1990) defined psychological safety as "an employee's sense of being able to show and employ one's self without fear of negative consequences to selfimage, status or career". Embedding adequate PS is crucial for innovation performance. Creative and innovative outcomes in the workplace result from a complex interaction among the employees at different levels of the organization. If these interactions lead to feelings of well-being, high selfesteem, and motivation, the employees will become more inclined to stretch him or herself to utilize discretionary effort and to become creative or innovative. PS in a work ca-

${ }^{*}$ corresponding author: Pari Irai

†email: jnrjparii@gmail.com 
pacity is basically about creating conducive working environments in which employees feel secured and motivated to share their opinions, ideas, and knowledge (Alshehhi, 2016; Edmondson, 1999).

\section{Statement of the Problem}

Education to economic growth and development are driven by innovation and technology. The fail system does not only harm the people that it is meant to serve, it costs more wealth to even run an inefficient agency. Lack of innovation within the government sector in Papua New Guinea (PNG) has long been blamed for its sluggish economy and service delivery throughout the country. The advancement in technology and innovation performance have forced organizations to cope with these constant developments. Likewise, there has been a tremendous pressure on Papua New Guinea Public Sectors to cope with these constant changes to be innovative and improve their service delivery. The Government of Papua New Guinea (GoPNG) must upgrade and innovate rapidly and continually in order to cope with the advancement in the world where progress to innovation comes quickly. No government official can assume only technology will cure their organization's woes. All forms of innovation and technology require intent and direction to produce a proper, valuable outcome. Therefore, to improve organizational innovation performance, creating conducive working environments, in which employees feel secured and motivated, and encouraging knowledge sharing behavior are critical to the government sector in PNG.

\section{Objectives of the Study}

The objective of this research is twofold.

1) This study aims to investigate the relationship of psychological safety and organizational innovation.

2) Secondly, this study intends to test the mediating effect of knowledge sharing on the relationship between psychological safety and organizational innovation.

\section{Significance of the Study}

The outcomes from the study will contribute to the improvement of PNG Public Sector as it seeks ways to be innovative. The outcomes to be considered consist of the following: provide the basis in which gaps in the public sector's systems can be identified and necessary actions will be taken to improve these systems and enhance organizational performance; the study will also make recommendations concerning the interventions which public sector can use to create a conducive working environment in which employees feel secured, motivated, and respected in their working environment, and are empowered and able to ex- press themselves more freely; the study will make recommendations for the organization to encourage and motivate employees' knowledge sharing behavior; And finally, the study will create a platform for future research to be conducted and further improve in the areas of psychological safety, knowledge sharing, and organizational innovation in the public sector.

\section{LITERATURE REVIEW}

\section{Papua New Guinea Public Sector}

According to the PNG Department of Personnel Management (DPM), public sector is governed under the DPM. Its purpose is integral to the management of other publicsector organizations or agencies as it acts as the central agency with the Government's policy initiatives and implementation to the public sector reforms. This fundamental role as the central agency of the GoPNG, National Public Services means the DPM plays a key role in providing and enhancing the aspects of strategic leadership and human resource management that stipulates and encourages decent working relationships among all agencies, thereby also facilitating service delivery of quality to the GoPNG and its people. As defined under the Public Service Management Act, it provides this strategic leadership in the three distinct areas which include employment, industrial relations, and human resource development and management.

It is the goal of the DPM to become the leader in human resources management and its delivery of government services throughout the country. The initiatives it embodies are vital to all agencies in the development of smarter, more efficient human resources policies, through the encouragement of ethical leadership throughout the public services sector. As a department, it intends to concentrate and prioritize emerging areas by monitoring and improving performances in the following areas:

- Record and disseminate decisions

- Develop information sharing opportunities

- Contribute to innovation

- Improve productivity

Thus, human resource management and its functions have been identified as significant and crucial to improving the roles of government in the delivery of its services in PNG.

\section{Organizational Innovation}

Despite the size of organization or industry, a culture of innovation is crucial to advance and succeed in the contemporary frequently ever-changing world. This need of innovation is evident daily. The advancement of digitalization continues to transform the way people engage themselves at 
work. Moreover, national and global phenomena continue to impact the way organizations function. Hence, organizational innovation is necessary in keeping up with these rapid changes. Mortensen and Bloch (2005) incorporated both the traditional and recent definitions more precisely. They defined organizational innovation as the application of a modern and innovative organizational procedure in organizational practices, workplace, or extraneous relationships. This definition implies that organizational innovation incorporates processes which lead organizations to establishing and adopting new production and management models. Johnson, Chang, and Yang (2010) added that the long-term success of organizations depends on its creativity to generate new products, systems, and service items that meet the demands of the client.

Organizational innovation can be different from other organizational changes and the features in that it implements new processes and procedures that other organizations do not use which results from strategic management decisions (Mortensen \& Bloch, 2005). This implies that the implementation of new process and procedures in the workplace to distribute responsibilities and decision-making amongst employees is the new concept of innovation. According to Oldham and Cummings (1996), the application of new methods within the organization is necessary for innovation and organization to engage these practices and procedures in order to establish databases of best practice, improve worker retention, or introduce management systems. Conclusively, the organizational methods for establishing and arranging external relationship with other organizations should be adopted and utilized in new ways and innovatively, such as collaborating with research-based organizations.

\section{Psychological Safety}

According to Kahn (1990) definition, it denotes that psychological safety is alternatively an individual psychological state than a personality trait that makes the individuals feel safe and self-assured that the immediate working environment is non-threatening to the personal well-being, hence, creating a conducive working environment, in which the individual will feel safe and not be agitated or penalized for expressing their opinions or themselves. This demonstrates that psychological safety is critical in the settings where certain behavior engaged by individuals may have put the individual's interest or security at stake, such as the fear of possible undesirable outcomes that might result from their behavior. Precisely, when an individual's psychological safety is high, the level of confidence in his behavior increases. Thus, the individual feels that the behavior is safe and the fear of causing negative consequences will decrease, which then permits the individual to maintain his behavior (Edmondson, 1999). Several studies have indicated that psychological safety is one of the crucial factors that affects different employees' work engagement and their behaviors to participate in the organizations. For example, psychological safety is perceived as an element in the workplace that raises the level of employee's personal engagement (Kahn, 1990). Other studies have also empirically supported this notion (May, Gilson, \& Harter, 2004).

\section{Knowledge Sharing}

Knowledge sharing is the process of exchanging both tacit and explicit knowledge among employees in order to create new knowledge (Au, 2016; Nonaka, 2008). Senge (1998) conceded that Knowledge sharing results when individuals become genuinely concerned for the development and advancement of capacities for action in others. In an attempt to meet organizational objectives and goals, many organizations have begun to champion this knowledge sharing behavior among employees. Some organizations have even claimed to have profited from the implementation of knowledge sharing strategy (Alam, Abdullah, Ishak, \& Zain, 2009; Bo Shing \& Xiaodie, 2017). However, Szulanski (1996) and Llorens, Bakker, Schaufeli, and Salanova (2006) noted that knowledge sharing remains a challenge for many organizations. Generally, individuals remain unwilling to share knowledge unless convinced of its importance and relevance (Llorens et al., 2006). According to Hidding and Catterall (1998), knowledge becomes useless when not shared or put to use. It appears that this unwillingness might be linked to the idea that by sharing knowledge, an individual unwittingly harms their uniqueness or equity (Husain \& Husin, 2017; Hendriks, 1999).

\section{Psychological Safety and Innovation}

The world is constantly changing at an increasing pace. Thus, in this period, organizations must seriously innovate or will face decline or extinction. Many organizations are seeking ways and adopting measures to strengthen their ability to remain innovative. According to Salaman and Storey (2002), innovation has fast become an important tool for competitive advantages. Eren (1982) states that innovation has made it possible for organizations by providing strategic advantages, for example costs reduction, new product and service disparity, and improved quality. It is clear that innovation brings development and improvements to organizational production, processes, and prac- 
tices in services and in order to achieve this innovation performance, the employee's voice must be heard. By openly communicating their views and performance-related concerns, employees assist their organizations to develop innovative ideas as well as to successfully adapt to everchanging corporate atmospheres (Dyne, Ang, \& Botero, 2003). Undeniably, employees' voice to improve current work-related failures is associated with positive organizational outcomes (Edmondson, 1999; Silahtaroglu, 2016). This realization of the crucial role of employees' voice, in the achievement of organizational effectiveness and avoidance of possible crises, has allowed researchers to understand the individual, motivational, and related factors that promote or inhibit voice (Kish-Gephart, Detert, Treviño, \& Edmondson, 2009).

Likewise, when employees feel safe about openly voicing their opinions, the perceived costs of sharing these opinions are minimized. Consequently, the benefits of voice outweigh the costs, leading to a more positive behavior (Zhao \& Olivera, 2006). For employees to feel safe in taking interpersonal risks, expressing themselves, and contributing to the work process, there must be a conducive work environment that encourages such behavior (Edmondson, 1999). A climate of psychological safety depicts an environment where employees are encouraged to contribute without fear of being rejected or punished. It is believed that employees who work in a non-threatening and supportive environment are more likely to propose new ideas as compared to those working in an environment where proposing a new idea will lead to an attack, being censored, ridiculed or penalized (West, 1990). Hence, organizations that cultivate a climate or environment for psychological safety improve employees' participative behaviors, along with the utilization of creative potential in employees. Such behavior leads to higher employee performance levels. Thus, some potential mechanisms, by which such working environment can be produced, include: ease or reduced risk in presenting new ideas in a safe climate (Edmondson, 1999), more effective team learning (Edmondson, 1999), greater job involvement and use of greater effort (Brown \& Leigh, 1996), and smoother collaboration in solving problems.

Furthermore, the working environment must permit the employees to take the risk of openly proposing new ways of working and suggesting alternative problem-solving approaches. Arguably, a climate that encourages employees to speak up and take risks complements the implementation and endorsement of modern process innovations, thus performing as a crucial prospect in developing the full potential of innovations. Thus, it is proposed that psychologi- cal safety is positively related to innovation.

\section{The Mediating Role of Knowledge Sharing}

In an era of knowledge-based economy, resource has become a crucial factor for organizations' survival in terms of competition and innovation (Subramaniam \& Youndt, 2005; Teece, Pisano, \& Shuen, 1997). According to present literature, knowledge is becoming a fundamental aspect that can strengthen a firm's core competencies, thereby helping to provide necessary resources for an organization to compete and remain innovative (Bollinger \& Smith, 2001; Teece, 1998). In addition, the willingness of employees to share knowledge with other employees within the organization is bet on the social relationships and structures that are incorporated by the organization (N. Lin, 1999). According to Nahapiet and Ghoshal (1998), this exchange of knowledge within the organization with parties, who have access to it, is facilitated by the social capital. Social capital is the connection that aids the cooperation among employees who share common norms, knowledge, and understanding (Inkpen \& Tsang, 2005). Social capital is crucial to creating mechanisms by which knowledge can be transmitted and accessed among employees (Makino \& Inkpen, 2003). It also enhances the efficiency of KS.

According to Edmondson (1999), a unit, whose members feel safe taking interpersonal risks without fear of embarrassment, rejection or punishment for speaking up, usually enjoys good interpersonal relationships and shares the desire to cultivate a safe psychological environment. An individual's psychological state helps to determine their surrounding interpersonal relationships. When psychological safety is high, employee will feel confident about his interpersonal behavior which, in turn, will encourage the employee to self-express and voice ideas. This indicates that PS is an important concern affecting the participative behavior of employees. This is supported by Kahn (1990), psychological safety increases the level of employee's personal engagement in the workplace. Kahn (1990) further stated that PS is beneficial in promoting individual's behavior, such as self-expression. Detert and Burris (2007) further discovered that an individual's improvement-oriented speaking behavior was similarly positively influenced by their sense of psychological safety. More recent studies have also discovered the importance of psychological safety on knowledge sharing behavior amongst employees (Siemsen, Roth, \& Balasubramanian, 2008).

As stated by Hoof, Ridder, and Aukema (2004), the availability of knowledge has become an important strategic tool on which many firms in this knowledge-based society 
rely. In fact, knowledge remains the central resource for many organizations in the maintenance of sustainable operations against rapid industrial and technological changes. Several studies (Gurteen, 1999; Liebowitz, 2002; H. F. Lin, 2007) indicate a link between knowledge sharing and the increase in an organization's innovative ability and performance. Jantunen (2005) alluded to this by reasoning that a firm's ability to think innovatively might be tied to its attitude towards knowledge sharing and donating. Thus, knowledge sharing should be an important mediating factor for psychological safety and organizational innovation. Therefore, in summary, the following hypotheses are proposed:

H1: Psychological safety is positively related to organizational innovation.

H2: Psychological safety is positively related to knowledge sharing.

H3: Knowledge sharing is positively related to organizational innovation.

H4: Knowledge sharing mediates the positive relationship between psychological safety and organizational innovation.

\section{Research Model and Hypothesis}

Figure 1 establishes direct and indirect, positive relationships between the variables. The framework illustrates the relationship between the independent, dependent, and mediating variables. It aims to find out whether psychological safety and organizational innovation have a cause-effect relationship. It also seeks to find out whether knowledge sharing has the potential to mediate the relationship of psychological safety and organizational innovation.

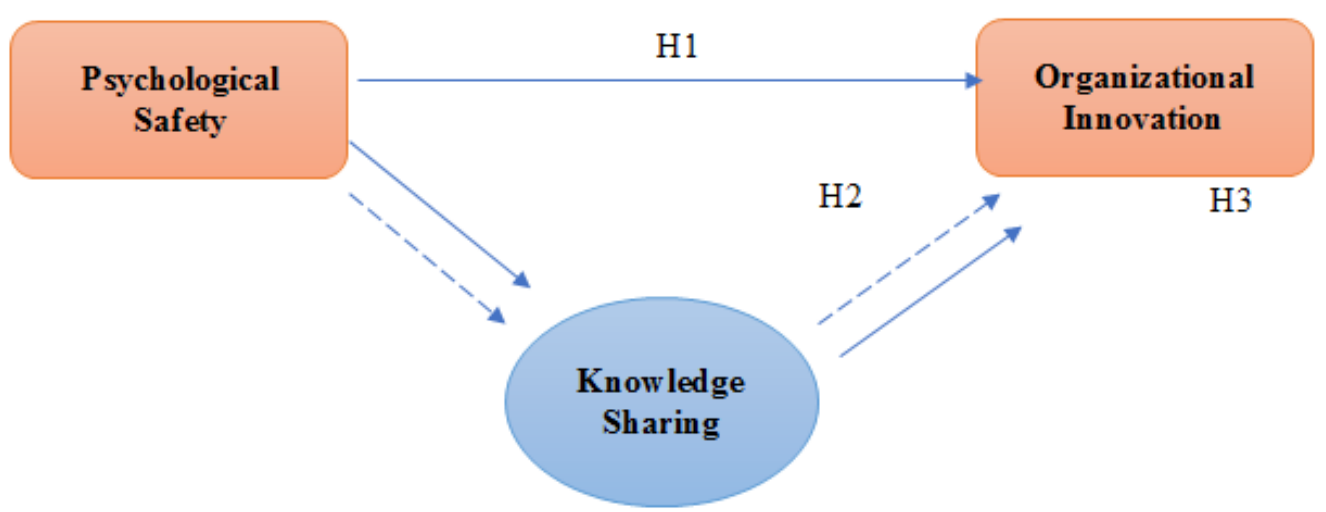

FIGURE 1. Hypothesis model

\section{RESEARCH METHODOLOGY}

\section{Research Sample \& Data Collection}

This study used quantitative research method. The participant population comprised of different government agencies in PNG public sector. The ensuing research relied upon the collection of data from individual respondents through the means of self-administered questionnaires. The respondents were provided with the options of pen-and-paper surveys and online surveys. The questionnaires were distributed to employees of the mentioned sector, and it took approximately two months for completion. The sample population consisted of 160 employees. Respondents remained completely anonymous. In addition, the survey sought the assistance of employers in the completion of survey during office hours. Furthermore, this study used nonprobability sampling in which snowball technique was engaged. This sampling technique was selected because of the accessibility to the samples in which each member of the organization was approached, knows their colleagues and who assisted in facilitating the distribution of questionnaires and collection of data. Moreover, this technique enabled the research to reach larger sample size which gave the advantage of providing more data to work with.

\section{Research Instrument}

Measurement items for this study were adopted from the previous research literatures contextual consistency. Each respondent in the study completed the questionnaires for three different variables: psychological safety, knowledge sharing, and organizational innovation. Items of knowledge sharing were adopted from Bock, Zmud, Kim, and Lee (2005), Items of psychological safety were adopted from (Brown \& Leigh, 1996; May et al., 2004), and items of organizational innovation were based on Miller and Friesen 
(1983). The variables to measure the constructs are described as the following which its Cronbach's alpha: knowledge sharing has 5 items $(\alpha=.91)$, PS has 5 items $(\alpha=.74)$, and organizational innovation has 9 items. The items of organizational innovation include the three 1: Process Innovation ( $\alpha=.85), 2$ : Product Innovation ( $\alpha=.81)$, and 3: Administrative Innovation $(\alpha=.92)$. All of the scales were measured on a 5-Point Likert Scale range; (1) being strongly disagree to (5) being strongly agree. Towards the end of the survey, there were several questions included to obtain demographic information of the respondents, such as gender, age, occupation, and education level.

A pretest was performed in ensuring the reliability and face validity of all the questions. Three professors, who are experts in the subject of this study, assessed the instrument clarity, question wording, ease of understanding and validity, logical consistencies, sequence of items, and contextual relevance. The comments and feedbacks from these three professors were adopted to revise problematic items.

\section{Data Analysis}

After the data for the study were collected, Statistical Package for the Social Science (SPSS) 22 software was used in analyzing the data. For the requirement of analysis, the employees' responses were combined and a single dataset was created. The final sample of 160 employees was collected. For examining the four hypotheses, three simple linear regression analyses were performed for H1, H2, H3 while Baron and Kenny (1986) mediation test approach was performed for H4. Descriptive statistics were calculated for each variable and a correlation matrix of all variables was created.

\section{Testing the Hypothesis and Mediation with Regression Analysis}

Baron and Kenny (1986) four-step approach to test mediation with regression analysis was used and several regression analyses were conducted in which significance of the coefficients was tested at each of these steps. The Figure 2 and Table 1 below demonstrate the description to be followed (note that c' could also be represented as a direct effect).

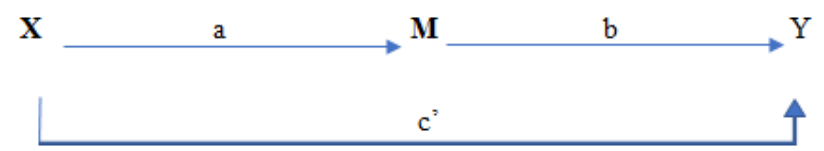

FIGURE 2. Testing hypothesis

TABLE 1. Regression analysis approach

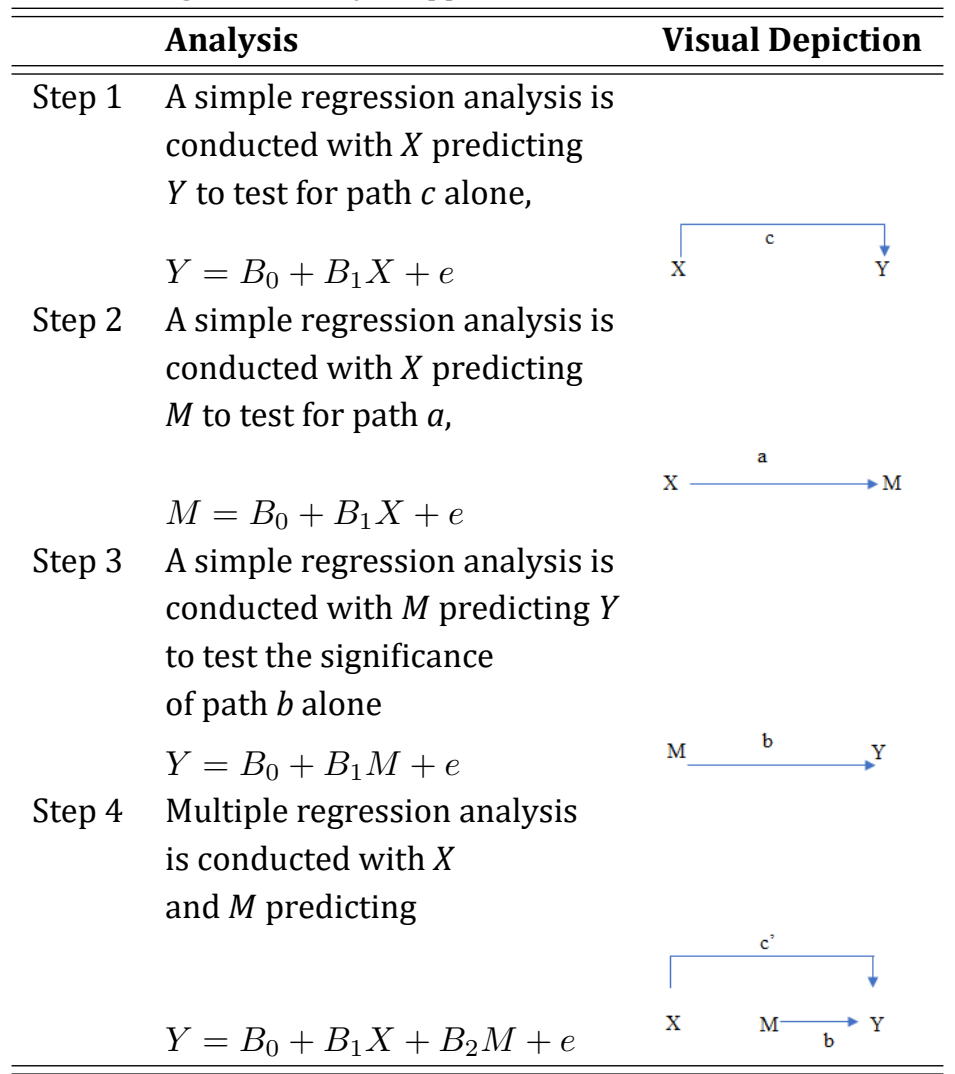


Given the steps 1-3, the purpose is to determine the existence of zero-order relationships amongst the variables. Supposing that one or more of these relationships are insignificant, the researcher should generally conclude that the mediation is unrealistic or more likely, though such cannot be true in most instances (MacKinnon, Fairchild, \& Fritz, 2007). Supposing the result is otherwise means that the relationships are significant from Steps 1 through 3 and progresses to Step 4. In Step 4, some form of mediation will be supported if the effect of $M$ (path $b$ ) remains significant after controlling for $X$. In case that $X$ is no longer significant when $M$ is controlled, the finding supports full mediation. If $X$ is still significant (i.e., both $X$ and $M$ significantly predict $Y$ ), the finding supports partial mediation.

\section{RESULTS}

\section{Tests for Hypotheses}

Though Hypothesis 4 was concerned with test for mediation, the other three hypotheses were efficiently tested using the procedures indicated in Table 1 . Table 2 presents the results of the first regression, in which psychological safety was regressed on organizational innovation and the control variables.

TABLE 2. Descriptive statistics, reliability coefficients, and correlations among the variables

\begin{tabular}{lccccc}
\hline \hline Variable & Mean & SD & $\mathbf{1}$ & $\mathbf{2}$ & $\mathbf{3}$ \\
\hline 1. Psychological safety & 3.32 & .61 & .809 & & \\
2. Knowledge sharing & 4.24 & .65 & $.273^{* *}$ & .838 & \\
3. Organizational innovation & 3.36 & .71 & $.269^{* *}$ & $.230^{* *}$ & .861 \\
\hline
\end{tabular}

Note: Parentheses numbers denote reliability coefficients ${ }^{* *} P<.01$

As results showed, there was a positive relationship for $\mathrm{H} 1$ $(b=0.269, p<0.01)$. Also, there was a significant positive relationship between psychological safety and knowledge sharing, $\mathrm{H} 2(b=0.272, p<0.01)$, and between knowledge sharing and organizational innovation, $\mathrm{H} 3(b=0.230, p<$ 0.01). All these results support $\mathrm{H} 1, \mathrm{H} 2$, and $\mathrm{H} 3$.

\section{Test for Mediation}

The analytical results showed a partial mediation effect of knowledge sharing on the relationship between psychological safety and organizational innovation. The effect of psychological safety and knowledge sharing together on organizational innovation has decreased but still remained significant when comparing with psychological safety's effect alone on organizational innovation $(b=0.223, p<.01)$. This denotes a direct and partial indirect effect (through knowledge sharing) of psychological safety on organizational innovation.

\section{DISCUSSION AND CONCLUSION}

\section{Conclusion}

This research sought to light up the role of psychological safety and knowledge sharing in influencing organizational innovation. Concisely, the results demonstrate that both psychological safety and knowledge sharing have a positive effect on organizational innovation, and that knowledge sharing partially mediates the effect of psychological safety on organizational innovation. Knowledge sharing is also positively influenced by psychological safety. Based on these findings, the willingness of people to share knowledge and ideas with other co-workers is determined by the state of their psychological safety in which it could also contribute more to organizational innovation.

\section{Implications for Practice}

This research affords to offer applicable implications for practice. First, the significance of psychological safety in the promotion of knowledge sharing and organizational innovation within the public sector has been exhibited. It is recommended that the managers and senior officers (e.g., the departmental heads) within the public sector must invest in the development of people's psychological safety if they want to stimulate cooperation among employees for the improvement and enhancement of organizational innovation. One way to achieve this is through employee encouragement and the creation of an atmosphere that supports and stimulates employees' impression that it is safe to voice their opinions and share knowledge. Managers should attempt to refrain from criticizing participants even when mistakes are made. The study experimented that this suggestion is applicable to knowledge sharing within public sector and also to the collaborations of knowledge resources within project teams (Zhang, Fang, Wei, \& Chen, 2010). Increased level of employees' involvement and engagement in the workplace creates rooms for new ideas' collaboration which enhances decision-making, quality, and 
morals which are the key factors in the implication of innovation. Second, since psychological safety acts as an antecedent of the knowledge sharing and organizational innovation, managers should work to create a favorable working atmosphere that encourages employees to voice their suggestions in team and inter-personal risk-taking with no threat of undesirable and negative implications that could cause harm to personal image, status or career. One possible strategy to achieve this is to create environments for collaboration amid organizational members, such as allowing the management of collaboration and teamwork, which can strengthen willingness to openly speak their views and express themselves. Thirdly, those who have high levels of fear for negative consequences turn to exhibit low levels of psychological safety and, therefore, tend to be reluctant to share their knowledge, which then affects the level of organizational innovation. Thus, special attention should be focused on such individual. One way to address this is to provide low level of psychological safety questions and allow them to answer these questions in order to find their level of psychological safety. For people with high levels of psychological safety, managers should apply extra effort toward them in order to reduce their concerns for undesirable and negative outcomes, and try to increase their view of psychological safety.

\section{Limitations and Directions for Future Research}

As with any research study, this study has its share of limitations that must be examined. Firstly, the participants em- pirically studied were public-sector employees. Thus, care should be taken in the process of applying the results to other situations and contexts. Bear in mind that the participants of those public agencies are professionals working on full-time basis. However, it must be added that it would be convincing and interesting to relate and compare public sector and private sector firms within the country, and examine whether or not the roles of psychological safety and knowledge sharing differ in promoting organizational innovation. Insights of such study would only expand our knowledge around the circumstances under which psychological safety and knowledge sharing are important to organizational innovation performance. Second, the attitudes to knowledge sharing were measured rather than the actual behavior to share knowledge. Many studies have shown that behavior to share knowledge and attitude to knowledge sharing differ. Future research could expand and investigate whether or not different dimensions of knowledge sharing can mediate the relationship between psychological safety and organizational innovation. Thirdly, using survey method, this study is also limited to cross-sectional design. Cross-sectional design could lead researchers to misidentify the causal relationship between independent and dependent variables while also making researchers unable to observe the changing patterns of subjects across time. Therefore, it is strongly recommended that future studies should cope with this issue by conducting longitudinal analysis in order to validate the model's stability over time and monitor variations and trends among subjects.

\section{REFERENCES}

Alam, S. S., Abdullah, Z., Ishak, N. A., \& Zain, Z. M. (2009). Assessing knowledge sharing behaviour among employees in smes: An empirical study. International Business Research, 2(2), 115-122. doi:https://doi.org/10.5539/ibr.v2n2p115

Alshehhi, A. S. (2016). Organizational knowledge systems. International Journal of Business and Administrative Studies, 2(6), 193-200. doi:https://doi.org/10.20469/ijbas.2.10004-6

$\mathrm{Au}$, T. D. (2016). Using open innovation model to enhance knowledge sharing in Vietnam university. Journal of Administrative and Business Studies, 2(5), 241-247. doi:https://doi.org/10.20474/jabs-2.5.4

Baron, R. M., \& Kenny, D. A. (1986). The moderator mediator variable distinction in social psychological research: Conceptual, strategic, and statistical considerations. Journal of Personality and Social Psychology, 51(6), 1173-1182. doi:https:// doi.org/10.1037//0022-3514.51.6.1173

Barquin, R. C. (2001). What is knowledge management? Knowledge and innovation. Journal of Knowledge Management Consortium International, 1(2), 127-143.

Black, D., \& Synan, C. (1997). The learning organisation: The sixth discipline? Management Accounting: Magazine for Chartered Management Accountants, 75(10), 70-72.

Bock, G. W., Zmud, R. W., Kim, Y. G., \& Lee, J. N. (2005). Behavioral intention formation in knowledge sharing: Examining the roles of extrinsic motivators, social-psychological forces, and organizational climate. MIS Quarterly, 29(1), 87-111. doi:https://doi.org/10.2307/25148669

Bollinger, A. S., \& Smith, R. D. (2001). Managing organizational knowledge as a strategic asset. Journal of Knowledge Management, 5(1), 8-18. doi:https://doi.org/10.1108/13673270110384365 
Bo Shing, L. A., \& Xiaodie, P. J. (2017). Exploring the relationship between leadership, organizational culture, trust, and effectiveness of knowledge sharing by forced learning. Journal of Administrative and Business Studies, 3(2), 89-104. doi:https://doi.org/10.20474/jabs-3.2.4

Brown, S. P., \& Leigh, T. W. (1996). A new look at psychological climate and its relationship to job involvement, effort, and performance. Journal of Applied Psychology, 81(4), 358-368. doi:https://doi.org/10.1037//0021-9010.81.4.358

Detert, J. R., \& Burris, E. R. (2007). Leadership behavior and employee voice: Is the door really open? Academy of Management Journal, 50(4), 869-884. doi:https://doi.org/10.5465/amj.2007.26279183

Dyne, L. V., Ang, S., \& Botero, I. C. (2003). Conceptualizing employee silence and employee voice as multidimensional constructs. Journal of Management Studies, 40(6), 1359-1392. doi:https://doi.org/10.1111/1467-6486.00384

Edmondson, A. (1999). Psychological safety and learning behavior in work teams. Administrative Science Quarterly, 44(2), 350-383. doi:https://doi.org/10.2307/2666999

Eren, E. (1982). İşletmelerde yenilik politikası: Kuram ve uygulamada yenilik. İstanbul, Turkey: İstanbul Üniversitesi İşletme Fakültesi.

Gurteen, D. (1999). Creating a knowledge sharing culture. Knowledge Management Magazine, 2(5), 1-4.

Hendriks, P. (1999). Why share knowledge? the influence of ICT on the motivation for knowledge sharing. Knowledge and Process Management, 6(2), 91-100. doi:https://doi.org/10.1002/(sici)1099-1441(199906)6:2<91::aid-kpm54>3.0 .co;2-m

Hidding, G. J., \& Catterall, S. M. (1998). Anatomy of a learning organization: Turning knowledge into capital at andersen consulting. Knowledge and Process Management, 5(1), 3-13. doi:https://doi.org/10.1002/(sici)1099-1441(199803) 5:1<3::aid-kpm8>3.0.co;2-o

Hoof, B. v. d., Ridder, J. d., \& Aukema, E. (2004). The eagerness to share: Knowledge sharing, ICT and social capital (Working paper). Amsterdam School of Communication Research, University of Amsterdam, Amsterdam, Netherlands.

Husain, Y. S., \& Husin, N. H. (2017). Knowledge sharing behavior, job attitudes, OCB and organizational learning culture. Journal of Administrative and Business Studies, 3(4), 162-170. doi:https://doi.org/10.20474/jabs-3.4.1

Inkpen, A. C., \& Tsang, E. W. (2005). Social capital, networks, and knowledge transfer. Academy of Management Review, 30(1), 146-165.

Jantunen, A. (2005). Knowledge-processing capabilities and innovative performance: An empirical study. European Journal of Innovation Management, 8(3), 336-349. doi:https://doi.org/10.1108/14601060510610199

Johnson, R. E., Chang, C.-H., \& Yang, L.-Q. (2010). Commitment and motivation at work: The relevance of employee identity and regulatory focus. Academy of Management Review, 35(2), 226-245. doi:https://doi.org/10.5465/ amr.2010.48463332

Kahn, W. A. (1990). Psychological conditions of personal engagement and disengagement at work. Academy of Management Journal, 33(4), 692-724. doi:https://doi.org/10.2307/256287

Kish-Gephart, J. J., Detert, J. R., Treviño, L. K., \& Edmondson, A. C. (2009). Silenced by fear: The nature, sources, and consequences of fear at work. Research in Organizational Behavior, 29, 163-193. doi:https://doi.org/10.1016/ j.riob.2009.07.002

Liebowitz, J. (2002). Facilitating innovation through knowledge sharing: A look at the us naval surface warfare centercarderock division. Journal of Computer Information Systems, 42(5), 1-6.

Lin, H. F. (2007). Knowledge sharing and firm innovation capability: An empirical study. International Journal of Manpower, 28(3/4), 315-332. doi:https://doi.org/10.1108/01437720710755272

Lin, N. (1999). Building a network theory of social capital. Connections, 22(1), 28-51.

Llorens, S., Bakker, A. B., Schaufeli, W., \& Salanova, M. (2006). Testing the robustness of the job demands-resources model. International Journal of Stress Management, 13(3), 378. doi:https://doi.org/10.1037/1072-5245.14.2.224

MacKinnon, D. P., Fairchild, A. J., \& Fritz, M. S. (2007). Mediation analysis. Annual Review Psychology, 58, 593-614.

Makino, S., \& Inkpen, A. C. (2003). Knowledge seeking fdi and learning across borders. Handbook of Organizational Learning and Knowledge Management, 2(3), 231-252.

May, D. R., Gilson, R. L., \& Harter, L. M. (2004). The psychological conditions of meaningfulness, safety and availability and the engagement of the human spirit at work. Journal of Occupational and Organizational Psychology, 77(1), 11-37. doi:https://doi.org/10.1348/096317904322915892 
Miller, D., \& Friesen, P. H. (1983). Strategy-making and environment: The third link. Strategic Management Journal, 4(3), 221-235. doi:https://doi.org/10.1002/smj.4250040304

Mortensen, P. S., \& Bloch, C. W. (2005). Oslo manual-guidelines for collecting and interpreting innovation data: Proposed guidelines for collecting and interpreting innovation data. Organisation for Economic Cooporation and Development, OECD. Retrieved from https://bit.1y/1VhMLcc (accessed on 23 May 2017)

Nahapiet, J., \& Ghoshal, S. (1998). Social capital, intellectual capital, and the organizational advantage. Academy of Management Review, 23(2), 242-266. doi:https://doi.org/10.2307/259373

Nonaka, I. (2008). The knowledge-creating company. Brighton, MA: Harvard Business Review Press.

Oldham, G. R., \& Cummings, A. (1996). Employee creativity: Personal and contextual factors at work. Academy of Management Journal, 39(3), 607-634. doi:https://doi.org/10.5465/256657

Salaman, G., \& Storey, J. (2002). Managers' theories about the process of innovation. Journal of Management Studies, 39(2), 147-165. doi:https://doi.org/10.1111/1467-6486.00286

Senge, P. (1998). Sharing knowledge: You can't own knowledge, so why not share it? Executive Excellence, 15, 11-12. doi:https://doi.org/10.1002/(sici)1099-1441(199906)6:2<91::aid-kpm54>3.0.co;2-m

Siemsen, E., Roth, A. V., \& Balasubramanian, S. (2008). How motivation, opportunity, and ability drive knowledge sharing: The constraining-factor model. Journal of Operations Management, 26(3), 426-445. doi:https://doi.org/10.1016/ j.jom.2007.09.001

Silahtaroglu, . V. P., G. (2016). Leaders impact on organizational behavior: A text mining study on universities in Turkey. International Journal of Business and Administrative Studies, 2(2), 52-56. doi:https://doi.org/10.20469/ijbas.2.10005 $-2$

Subramaniam, M., \& Youndt, M. A. (2005). The influence of intellectual capital on the types of innovative capabilities. Academy of Management Journal, 48(3), 450-463. doi:https://doi.org/10.5465/amj.2005.17407911

Szulanski, G. (1996). Exploring internal stickiness: Impediments to the transfer of best practice within the firm. Strategic Management Journal, 17(S2), 27-43. doi:https://doi.org/10.1002/smj.4250171105

Teece, D. J. (1998). Capturing value from knowledge assets: The new economy, markets for know-how, and intangible assets. California Management Review, 40(3), 55-79. doi:https://doi.org/10.1142/9789812796929_0003

Teece, D. J., Pisano, G., \& Shuen, A. (1997). Dynamic capabilities and strategic management. Strategic Management Journal, 18(7), 509-533.

West, M. A. (1990). The social psychology of innovation in groups. In M. A. West, \& J. L. Farr (Eds.), Innovation and creativity at work: Psychological and organizational strategies. Oxford, UK: John Wiley \& Sons.

Zhang, Y., Fang, Y., Wei, K.-K., \& Chen, H. (2010). Exploring the role of psychological safety in promoting the intention to continue sharing knowledge in virtual communities. International Journal of Information Management, 30(5), 425-436. doi:https://doi.org/10.1016/j.ijinfomgt.2010.02.003

Zhao, B., \& Olivera, F. (2006). Error reporting in organizations. Academy of Management Review, 31(4), 1012-1030. doi: https://doi.org/10.5465/amr.2006.22528167 